\title{
The Consequences of Race for Police Officers' Responses to Criminal Suspects
}

\author{
E. Ashby Plant and B. Michelle Peruche
}

Florida State University

\begin{abstract}
The current work examined police officers' decisions to shoot Black and White criminal suspects in a computer simulation. Responses to the simulation revealed that upon initial exposure to the program, the officers were more likely to mistakenly shoot unarmed Black compared with unarmed White suspects. However, after extensive training with the program, in which the race of the suspect was unrelated to the presence of a weapon, the officers were able to eliminate this bias. These findings are discussed in terms of their implications for the elimination of racial biases and the training of police officers.
\end{abstract}

When in the field, police officers face difficult split-second decisions in which they must determine whether criminal suspects are armed and constitute an imminent threat. Tragic events, such as the shooting of Marquise Hudspeth by police officers who mistook the cellular phone that the young Black man was carrying for a weapon, have led people to question whether officers' split-second decisions to shoot may be influenced by the suspects' race. Consider that the stereotype of Black people includes characteristics such as aggressive and criminal (Brigham, 1971; Devine \& Elliot, 1995). This stereotype may create expectations that Black people, and particularly Black men, are more likely than White people to be violent criminals, which may lead to racially biased interpretations of suspects' behavior. If police officers possess such expectations, then their split-second decisions about whether or not to shoot at a suspect may be biased and result in more antagonistic responses to Black than White suspects.

Recent research has examined whether race influences people's decisions to shoot criminal suspects (e.g., Correll,

Address correspondence to E. Ashby Plant, Department of Psychology, Florida State University, Tallahassee, FL 32306-1270; e-mail: plant@ psy.fsu.edu.
Park, Judd, \& Wittenbrink, 2002; Greenwald, Oakes, \& Hoffman, 2003; Plant, Peruche, \& Butz, in press). For example, Correll et al. had undergraduates complete a computer simulation in which they had to determine whether a male suspect who appeared on screen was holding a gun or a neutral object. If the suspect had a gun, they were instructed to shoot by hitting a specified button. If the suspect had a neutral object, they were instructed to hit a specified "don't shoot" button. The participants were more likely to mistakenly shoot (i.e., shoot an unarmed suspect) when the suspect was Black than when the suspect was White (also see Payne, 2001).

However, recent evidence indicates that such biases can be eliminated. Plant and her colleagues (in press) had participants complete a computer simulation similar to the one used by Correll et al. (2002). Undergraduates pretending to be police officers decided whether to shoot Black and White male suspects on the basis of whether a gun was present in the picture. Although the participants were initially more likely to mistakenly shoot unarmed Black suspects than unarmed White suspects, after extensive practice with the program, in which the race of the suspect was unrelated to the presence of a weapon, this racial bias was eliminated both immediately after training and $24 \mathrm{hr}$ later. These findings indicate that repeated exposure to stimuli in which race is unrelated to the presence of a gun can eliminate race bias. Plant et al. argued that over the course of multiple trials, participants came to inhibit the activation of the racial category because race was nondiagnostic of weapon possession. As a result, participants eliminated the automatic influence of race on their responses. Additional findings were consistent with this argument: After training on the program, participants' responses on a word-completion task indicated that they were inhibiting racial concepts.

Given these findings with undergraduate students, it seems possible that police officers' responses to criminal suspects are influenced by the suspects' race, which could have tragic implications. Therefore, it is essential to consider whether police 
officers in fact have such racial biases and whether these biases can be eliminated with repeated exposure to a simulation in which the suspect's race is unrelated to the presence of a gun. To this end, in the present study, certified police patrol officers completed training with the computer simulation used by Plant et al. (in press). We expected that, as in the previous work with undergraduate participants, the officers' initial responses would reveal a bias toward mistakenly shooting unarmed Black suspects more often than unarmed White suspects. However, we anticipated that these biases would be eliminated after repeated exposure to the program, in which race was unrelated to weapon possession.

\section{METHOD}

\section{Participants}

Participants were 50 certified sworn law-enforcement personnel in the state of Florida (83\% male; 84\% White, 10\% Black, 2\% Native American, and 4\% Hispanic). The mean age of participants was 37 years, and law-enforcement experience ranged from 2 to 30 years $(M=12)$. Two officers made too few valid responses to the computer simulation (i.e., responded to less than $20 \%$ of trials within the time limit), leaving a sample of 48 officers.

Permission to recruit officers was initially obtained through the chiefs of police of the police departments. After we received authorization, we asked police officers to voluntarily participate in a project examining object perception. Officers were informed that their responses would remain completely anonymous, and that this anonymity was ensured because they would not be providing their name or any identifying information.

\section{Materials}

In order to test the current hypotheses, we used the computer simulation from the previous study by Plant et al. (in press). The program, which uses Inquisit software, instructed participants:

Today your task is to determine whether or not to shoot your gun. Pictures of people with objects will appear at various positions on the screen.... Some of the pictures will have a face of a person and a gun. These people are the criminals, and you are supposed to shoot at these people. Some of the pictures will have a face of a person and some other object (e.g., a wallet). These people are not the criminals and you should not shoot at them. Press the "A" key for "shoot" and press the "L" key on the keyboard for "don't shoot."

The program presented participants with digital color photographs of nine Black and nine White college-age males selected from a set of pictures matched for attractiveness (Malpass, Lavigueur, \& Weldon, 1974). A picture of a gun or a neutral object (e.g., wallet, cell phone), formatted to be equivalent in size and background, was superimposed on each of the faces. The gun or other object was positioned with the face still visible, but the location varied so that participants could not predict where the object would appear. Two stimuli were created for each face, one with a gun and one with a neutral object.

On each trial, the computer program randomly selected one of the pictures and displayed it on the screen. So that the program would be challenging, the picture randomly appeared toward the top, middle, or bottom of the screen and toward the right, center, or left of the screen. Each picture appeared on screen until the participant responded or until the 630-ms time limit elapsed. When a participant did not make a correct decision (i.e., hit the wrong key or exceeded the time limit), an error message appeared on screen for a full second. Each participant completed 20 practice trials and 160 test trials.

\section{Procedure}

The officers met the experimenter individually in a private office at their department headquarters and were seated at a desk with a laptop computer. They were told that the study was about decisions to shoot and how different factors influence these decisions. Participants read the consent form and agreed to participate, but did not sign the form so that their anonymity would be ensured. The experimenter provided instructions regarding the computer simulation, and the participants completed the program. After the simulation, participants were debriefed and thanked for their participation.

\section{RESULTS}

\section{Analyses of the Simulation Task}

In order to determine whether participants' performance on the simulation task revealed less bias on the later trials than the earlier trials, we split the trials in half and compared the responses on the first half of the trials with the responses on the second half. The error scores were submitted to a 2 (race of suspect: Black vs. White) $\times 2$ (object: gun vs. neutral $) \times 2$ (trial: early vs. late) repeated measures analysis of variance (ANOVA). This analysis revealed a main effect of trial, $F(1,47)=5.70$, $p<.03$, and a Race of Suspect $\times$ Object interaction, $F(1,47)=$ $5.35, p<.03$. However, this lower-order interaction was qualified by a Race of Suspect $\times$ Object $\times$ Trial interaction, $F(1,47)$ $=5.84, p<.03$ (see Table 1). Separate Race of Suspect $\times$ Object ANOVAs were conducted for the early and late trials in order to explore the nature of this interaction.

Analyses of the early trials revealed a Race of Suspect $\times$ Object interaction, $F(1,47)=10.66, p<.003$. The officers were more likely to mistakenly shoot at an unarmed suspect when the suspect was Black than when the suspect was White, $t(1,47)=-3.17, p<.002$. In contrast, when the suspect was armed, the officers were somewhat but not significantly more likely to mistakenly not shoot a White suspect than a Black suspect, $t(1,47)=1.60, p=.12$. 
TABLE 1

Mean Number of Errors as a Function of Trial, Race of Suspect, and Object

\begin{tabular}{llr}
\hline \hline & \multicolumn{2}{c}{ Race of suspect } \\
\cline { 2 - 3 } Trial half and object & White & Black \\
\hline Early trials & & \\
$\quad$ Gun & $3.63(2.64)$ & $3.10(2.27)$ \\
$\quad$ Neutral object & $2.65(2.14)$ & $3.63(2.45)$ \\
Late trials & $3.13(2.19)$ & $3.27(2.84)$ \\
$\quad$ Gun & $2.44(1.91)$ & $2.60(1.90)$ \\
$\quad$ Neutral object &
\end{tabular}

Note. Standard deviations are in parentheses.

Analysis of the error rates in the later trials revealed only a main effect of object, such that participants made more errors on trials with guns $(M=3.20, S D=2.52)$ than on trials with neutral objects $(M=2.52, S D=1.90), F(1,47)=4.79, p<$ .04 . There was no interaction between race of suspect and object, $F<1$.

\section{Signal Detection Analyses}

In evaluating responses to the program, it is useful to consider signal detection theory (Green \& Swets, 1966; Snodgrass \& Corwin, 1988). By examining participants' hits (i.e., shooting an armed suspect) and false alarms (i.e., shooting an unarmed suspect), we calculated the accuracy (i.e., $d^{\prime}$ ) of participants' decisions and the criterion that they used to make their decision (c). Decision criteria can range from liberal (e.g., the tendency to shoot) to conservative (e.g., the tendency not to shoot), with a criterion of 0 representing neither tendency.

On the basis of previous findings (e.g., Correll et al., 2002), we anticipated that the race of the suspect would not affect accuracy $\left(d^{\prime}\right)$ on the early trials of the computer task; however, we did expect the race of the suspect to influence the decision criterion $(c)$. Specifically, we anticipated that participants would use a more liberal criterion (i.e., be more likely to shoot) when responding to Black compared with White suspects. However, if exposure to the training program eliminated biases, then participants would shift to a more conservative criterion when responding to Black suspects on the later trials.

Participants' $d^{\prime}$ and $c$ scores were submitted to 2 (race of suspect: Black vs. White) $\times 2$ (object: gun vs. neutral) $\times 2$ (trial: early vs. late) repeated measures ANOVAs. The analysis of $d^{\prime}$ revealed only a main effect of trial, such that participants responded with higher overall accuracy on the later trials $\left(d^{\prime}=\right.$ 1.89) than the earlier trials $\left(d^{\prime}=1.55\right), F(1,47)=20.87, p<$ .001 . These findings indicate that the race biases apparent in responses to the early trials were not due to poorer accuracy on trials with Black suspects than on trials with White suspects.

There was also a main effect of trial for $c$ scores, such that participants responded with more conservative criteria for later trials $(c=.05)$ than earlier trials $(c=-.05), F(1,47)=5.20$, $p<.03$. The analysis also revealed a main effect of race of suspect, with participants showing more liberal criteria (i.e., tendency to shoot) for Black suspects $(c=-.06)$ compared with White suspects $(c=.06), F(1,47)=9.63, p<.004$. However, this analysis also resulted in a marginal Race of Suspect $\times$ Trial interaction, $F(1,47)=2.90, p<.10$. Planned comparisons revealed that, as predicted, participants responded with more liberal criteria for Black suspects on early trials $(c=-.12)$ than for White suspects on early trials $(c=.04), t(47)=-4.11, p<$ .001 . However, for the late trials, participants were similarly conservative in response to the Black $(c=.02)$ and White $(c=$ .07 ) suspects, $t(47)=-0.96, p=.34$. Further, comparison of the criteria across the early and late trials revealed that participants shifted their responses to the Black suspects to be more conservative on the late than the early trials, $t(47)=$ $-2.82, p<.008$, but they did not alter their responses to the White suspects, $t(47)=-0.68, p=.50$.

\section{DISCUSSION}

This experiment investigated police officers' decisions to shoot Black and White criminal suspects in a computer simulation. Examination of the officers' responses revealed that, as in previous work using undergraduate samples (e.g., Correll et al., 2002; Plant et al., in press), the officers were initially more likely to mistakenly shoot unarmed Black suspects than unarmed White suspects. These findings are troubling because racial biases in officers' responses to criminal suspects could have tragic implications if such biases generalize to real-life decisions. However, on a more promising note, after extensive exposure to the program, the officers were able to eliminate this bias. Specifically, although the officers were biased toward mistakenly shooting unarmed Black more than unarmed White suspects on the early trials, this bias was eliminated on the later trials. Thus, exposure to the program, in which the race of the suspect was unrelated to the presence of a weapon, eliminated the racial bias. Unlike much of the previous work demonstrating the existence of racial biases in decisions to shoot and in weapon identification (e.g., Correll et al., 2002; Payne, 2001), the current study is heartening and indicates that, although such biases exist in police officers' responses to computer simulations, they are not inevitable and may be eliminated.

Signal detection analyses demonstrated that exposure to the simulation resulted in a shift in participants' decision criteria for Black suspects, from a liberal bias toward shooting on early trials to a more conservative response on later trials that was consistent with participants' responses to White suspects. It is also worth noting that over the course of the trials, the officers were becoming more accurate in their responses to the simulation (i.e., they were making fewer errors regardless of race and weapon possession). Thus, exposure to the program had the added benefit of reducing all types of mistakes. 
Overall, these findings are encouraging and suggest that it may be possible to eliminate racial biases in responses to criminal suspects. However, it is important to note that there is currently no evidence that the elimination of bias in response to the simulation generalizes to other types of responses (e.g., decisions in the field). Indeed, learning is often quite domainspecific. Currently, officers train on programs (e.g., Firearms Training Systems, or FATS) that provide realistic simulation environments for officers to practice response accuracy in various "use of force" scenarios. Future work should explore the generalizability of the elimination of racial bias on the computer simulation used in the current work to other types of responses (e.g., FATS, decisions in the field). If responses generalize, training on such simulations may provide an important tool for eliminating racial biases and improving overall accuracy in police officers' decisions to shoot.

\section{CONCLUSIONS}

The aim of this study was to demonstrate that racial biases in responses to criminal suspects, although present among some police officers, are not inevitable and can be overcome with training on a computer simulation in which race is nondiagnostic. Our hope is that the current work provides a critical first step toward understanding the factors that influence (and potentially eliminate) racial biases in police officers' responses to criminal suspects.

\section{REFERENCES}

Brigham, J.C. (1971). Ethnic stereotypes. Psychological Bulletin, 76, $15-38$.

Correll, J., Park, B., Judd, C.M., \& Wittenbrink, B. (2002). The police officer's dilemma: Using ethnicity to disambiguate potentially threatening individuals. Journal of Personality and Social Psychology, 83, 1314-1329.

Devine, P.G., \& Elliot, A.J. (1995). Are racial stereotypes really fading? The Princeton trilogy revisited. Personality and Social Psychology Bulletin, 21, 1139-1150.

Green, D.M., \& Swets, J.A. (1966). Signal detection and psychophysics. Huntington, NY: Robert E. Krieger.

Greenwald, A.G., Oakes, M.A., \& Hoffman, H.G. (2003). Targets of discrimination: Effects of race on responses to weapon holders. Journal of Experimental Social Psychology, 39, 399-405.

Malpass, R.S., Lavigueur, H., \& Weldon, D.E. (1974). Verbal and visual training in facial recognition. Perception \& Psychophysics, 14, 285-292.

Payne, B.K. (2001). Prejudice and perception: The role of automatic and controlled processes in misperceiving a weapon. Journal of Personality and Social Psychology, 81, 181-192.

Plant, E.A., Peruche, B.M., \& Butz, D.A. (in press). Eliminating automatic racial bias: Making race non-diagnostic for responses to criminal suspects. Journal of Experimental Social Psychology.

Snodgrass, J.G., \& Corwin, J. (1988). Pragmatics of measuring recognition memory: Applications to dementia and amnesia. Journal of Experimental Psychology: General, 117, 34-50.

(RECEIVED 3/23/04; REvision ACCEPTED 7/1/04) 